\title{
Gender Differences in Work Experiences and Work and Learning Outcomes among Employees in the Manufacturing Sector in Turkey: An Exploratory Study
}

\author{
Prof. Dr. Mustafa Koyuncu (Çanakkale Onsekiz Mart University, Turkey) \\ Asst. Prof. Dr. Fusun Tekin Acar (Erciyes University, Turkey) \\ Prof. Dr. Ronald J Burke (York University, Canada) \\ Kadife Koyuncu (Çanakkale Onsekiz Mart University, Turkey)
}

\begin{abstract}
This study examined gender differences in work experiences and work outcomes among 215 male and 46 female employees working in the textile and furniture sectors in Turkey. Data were collected from 261 employees, a 65 percent response rate, using anonymously completed questionnaires. Respondents were mostly male, worked full-time, had relatively short job and firm tenures, generally held jobs involving some supervisory responsibilities, and worked 41 to 50 hours per week in fairly large firms. All measures used here had been used and validated previously by other researchers. Work experiences included perceptions of supervisor empowering behaviors; outcomes included job satisfaction, affective commitment, work engagement, engaging in voice behaviors, and intent to quit. Learning related outcomes included learning opportunities and self-rated employability. There were small differences in departments in which men and women worked with a slightly higher percentage of men in production and a slightly lower percentage of men in accounting, human resource management and marketing. Consistent with earlier work, significant gender differences were found on several personal demographic and work situation characteristics. Women were younger, less likely to be married, were more highly educated, were at lower organizational levels, had less job and organizational tenure. Males and females had similar perceptions of their supervisor's empowering behaviors, their own levels of psychological empowerment, similar learning opportunities and levels of self-rated employability and on most work outcomes (e.g, job satisfaction, organizational commitment, intent to quit).
\end{abstract}

\section{Introduction}

This study examined potential gender differences in work experiences, important work outcomes typical of organizational research (e.g., job satisfaction, work engagement), as well as workplace learning-related opportunities and potential benefits of these to levels of worker employability. In addition, the study was undertaken in Turkey to address the relative lack of research undertaken there on women in management and the professions. The Turkish society and culture may also pose additional challenges to women in the workplace.

Supervisor empowering behaviors and psychological empowerment

Organizational cultures that empower employees are more likely to realize higher levels of employee and organizational performance (Bowen and Lawler, 1995, 1992; Menon, 2011; Quinn and Spreitzer, 1997, Zemke and Schaaf, 1989). Empowered employees have a more proactive view of their jobs bringing more energy, dedication and risk taking to their work.

Empowerment exists at two levels, macro or organizational and micro or individual (Spreitzer, 1997; Quinn and Spreitzer, 1997). Macro factors exist at the organization level and include organizational structure and hierarchy, policies, practices, and leader behaviors. Micro level empowerment considers individual perceptions and feelings of empowerment.

Work outcome benefits of empowerment

Empowered employees have been found to report more positive work outcomes. These would include higher levels of job satisfaction, work engagement, organizational commitment and lower levels of quit intentions (Seibert, et. al, 2011), which in turn get translated into higher levels of organizational success (Zemke and Schaaf,1989 ; Lawler, 1992; Lawler, et. al, 1995).

Workplace learning

Organizations that learn are likely to have competitive advantages given the increasing number of challenges they face in the form of heightened competition, the faster pace of change, increasing use of new technologies and processes, and the need for higher levels of innovation, among others (Salas and Von Glinow, 2008). Organizations however do not learn; individuals in organizations are the agents of all learning that takes place within organizations.

Organizations that exhibit high levels of individual learning have learning cultures, such cultures supporting learning at individual, team and organizational levels. Marsick and Watkins (2003) suggest seven dimensions of a learning culture, developed measures of these, and using a number of samples, showed a link between more supportive learning cultures and organizational performance. 
Individual learning in the workplace takes place formally through training initiatives dictated by the organization as well as informally through one's work experiences. Some writers have concluded that informal learning is more useful to individuals and their organizations than formal organization-sponsored learning events. We have come to better understand barriers, facilitators, and outcomes of informal workplace learning (Crouse, et. al, 2011; Lohman, 2009, 2006, 2005, 2000) and thus how to enhance it.

\section{Employability}

Another important outcome for both individuals and organizations from workplace learning is the concept of employability. Rothwell and Arnold (2007, p.75) define employability as "the individual ability to keep the job one has and of getting the job one desires". Individuals, through informal learning, acquire skills, behaviors, attitudes, values, relationships, information, and knowledge which helps them perform their present jobs at a high level and makes it more likely to advance their careers inside or outside their present organization. Employability has been found to predict objective early career success and the number of promotions for late career employees (vander Heijden, et. al, 2009). Interestingly, individuals having higher levels of self-rated employability were more rather than less likely to remain with their employers (DeCuyper and deWitte, 2011) appreciating what their employers did to contribute to their employability.

\section{Women in management and the professions in Turkey}

There are reasons for both optimism and pessimism as far as women's job prospects and career advancement in Turkey are concerned. Turkey has a significant number of women working as physicians, dentists, pharmacists, lawyers, and professors, but few of these women are at senior levels in these occupational groups. Women also have a presence in the public sector. (Kabasakal, et. al, 2011; Kabasakal, et. al, 2004; Boydak and Akpinar, 2002)

In addition, studies of gender differences in several occupations showed that although women and men differed considerably on personal demographic and work situation characteristics (e.g, women were younger, less likely to be married or have children, had lower salaries, were at lower organizational levels) gender differences on work outcomes such as job satisfaction, work engagement, intent to quit were few and small (Burke, et. al, 2009; Burke, et. al, 2011; Koyuncu, et. al, 2006).

There are some reasons for pessimism as well. The Republic of Turkey was created in 1923 with Mustafa Kemal Ataturk as president. He appeared to have very progressive attitudes towards the role of women, very much ahead of his time. However the current President of Turkey, Recep Tayyip Erdogan. Speaking in Istanbul at a meeting of an association advocating women's rights, said that gender equality goes against nature, pregnant women should not be in the same situation as working men, a woman breast feeding a child is not equal to a man, that Islam worships women ad mothers and that working women should instead stay at home with their children, and attacked feminists for not accepting the concept of motherhood. Women and men cannot be equal as they have different natures and bodies. Turkey is a secular Islamic country but Erdogan is trying to move the country in a more Islamic direction.

Here is some research evidence. Aycan (2004) found that Turkish men held stereotypes views of the managerial job and women in management. Guney, et. al, (2006), in a study of male and female teachers in Turkey and Pakistan reported that both men and women in Turkey had negative attitudes towards women managers, more so than did Pakistani male and female teachers. Besler and Oruc (2010) examined the portrayal of men and women in the media finding support for the "think manager, think male" viewpoint. Sanal (2008) noted the following factors as barriers to women's advancement: gender role stereotypes, conflict of work with roles of wife and other, men's negative attitudes to women in management (e.g., women less competent) and the "old boys" network. Women are always paid less than men holding the same jobs (Kabasakal, et. al, 2011). Ozbilgin and his colleagues (Ozbilgin 2000; Ozbilgin and Healy, 2004; Ozbilgin and Woodward, 2004a, Ozbilgin and Woodward, 2004b; Woodward and Ozbilgin, 1999) have highlighted the special challenges face in the financial, banking and university sectors in Turkey. Though women are entering educational offerings at all levels, more men than women receive the highest levels of education and men more than women tend to focus on the technological areas (Kabasakal, et. al, 2011).

Few private sector organizations make efforts to support the career advancement of their qualified female employees and though legislation supporting gender equality exists it is not clear the extent to which it is monitored or sanctions applied to organizations that fail to comply with it (Burke and Koyuncu, 2013).

Finally, a United Nations Development Programme (2008) report comparing the percentages of women among managers, legislators and union officials in 13 countries indicated that Turkey placed last having only $7 \%$ of these positions occupied by women as opposed to $52 \%$ in the United States, $37 \%$ in Germany and $36 \%$ in Canada.

\section{The present study}

In this study, we consider the relationship of employee perceptions of supervisor/leader empowerment behaviors, levels of felt psychological empowerment, important work outcomes (job satisfaction, affective organizational commitment, work engagement, engaging in voice behavior, intent to quit), and opportunities for 
learning and employability. Although the wider Turkish society and culture poses significant challenges to women in the workforce, women and men have been shown to have similar work experiences and outcomes.

We examine the following general hypotheses based on previous research findings.

1. Female employees with be significantly different from male employees on personal demographic and work situation characteristics.

2. Female and male employees will report similarly positive work experiences and work outcomes.

3. Female and male employees will report similar learning opportunities and self-rated employability.

\section{Method}

\subsection{Procedure}

The Employment Agency of the Kayseri Region of Turkey was approached in 2014 and indicated there were 58 furniture and 37 textile manufacturing organizations in their region. Fifty organizations, 30 from the furniture sector and 20 from the textile sector, were randomly selected to participate in the research. A total of 400 questionnaires were sent to these 50 organizations. Data were collected over a five month period, September 2014 to January 2015).Two hundred and sixty one individuals completed the survey, a $65 \%$ response rate.

\section{Respondents}

Table 1 presents the personal demographic and work characteristics of our sample $(\mathrm{n}=261)$. Most were male $(82 \%)$, worked full time (96\%), were between 31 and 40 years of age $(43 \%)$, were married $(71 \%)$, had children (87\%), had high school educations (38\%), worked in their present jobs between 1 and 5 years $(44 \%)$, worked for their present organization between 1 and 5 years (40\%), held non-management positions ( $35 \%$ ), earned between $\$ 5000-\$ 10,000$ US $(50 \%)$, worked between 41 and 50 hours per week $(82 \%)$, worked in a variety of departments but mostly in production (63\%), worked mostly in the furniture sector $(66 \%)$, and in organizations having 250 or more employees (44\%).

\subsection{Measures}

All measures used in the research were translated from English to Turkish and back by members of the research team fluent in both languages using the back translation method.

Personal and work situation demographics

Personal and work setting characteristics were assessed by a number of single items. The former included: gender, age, current work status, current marital and parental status, and level of education. The latter included hours worked per week, organizational level, job tenure, organizational tenure, and whether respondent had supervisory duties. These items served as control variables in some of our analyses.

Supervisory empowerment behaviors

Arnold, et. al, (2000) developed and validated a measure of empowering leader behaviors. They ended up with five factors: Coaching, Informing, Leading by example, Participative Decision Making, and Showing concern/Interacting with their team. In the present research, each of these five dimensions was measured by five items. Respondents indicated how frequently their supervisor exhibited each behavior on a five point Likert Scale $(1=$ Never, $3=$ Sometimes, $5=$ Always $)$. 


\begin{tabular}{|c|c|c|c|c|c|}
\hline Gender & $\underline{N}$ & $\underline{\%}$ & Age & $\underline{\mathrm{N}}$ & $\underline{\%}$ \\
\hline Male & 215 & 82.4 & 20 or less & 8 & 3.1 \\
\hline \multirow[t]{2}{*}{ Female } & 46 & 17.6 & $21-30$ & 80 & 31.1 \\
\hline & & & $31-40$ & 112 & 43.6 \\
\hline Work Status & & & $41-50$ & 49 & 19.1 \\
\hline Full time & 251 & 96.2 & 51 or more & 8 & 3.1 \\
\hline \multirow[t]{2}{*}{ Part time } & 10 & 3.8 & & & \\
\hline & & & $\underline{\text { Parental Status }}$ & & \\
\hline Marital Status & & & Children & 171 & 87.7 \\
\hline$\overline{\text { Single }}$ & 76 & 29.3 & No children & 24 & 12.3 \\
\hline \multirow[t]{2}{*}{ Married } & 183 & 70.7 & & & \\
\hline & & & Hours worked & & \\
\hline Education & & & 39 or less & 6 & 2.3 \\
\hline Elementary & 58 & 22.2 & 40 to 50 & 212 & 82.5 \\
\hline High school & 99 & 37.9 & 50 or more & 39 & 15.2 \\
\hline Bachelors & 91 & 34.9 & & & \\
\hline \multirow[t]{2}{*}{ Master/PhD } & 13 & 5.0 & $\underline{\text { Supervisory duties }}$ & & \\
\hline & & & Yes & 184 & 70.5 \\
\hline Organizational level & & & No & 27 & 29.5 \\
\hline Non-supervisory & 91 & 34.9 & & & \\
\hline Supervisor & 87 & 33.3 & Organizational tenure & & \\
\hline Middle management & 69 & 26.4 & 5 years or less & 103 & 39.9 \\
\hline \multirow{2}{*}{ Senior management } & 16 & 5.4 & 6 to 10 years & 74 & 28.7 \\
\hline & & & 11 to 20 & 67 & 26.0 \\
\hline Income (US\$) & & & 21 or more & 14 & 5.4 \\
\hline$\overline{5000 \text { or less }}$ & 34 & 13.0 & & & \\
\hline 5001 to 10,000 & 130 & 49.8 & Organizational size & & \\
\hline 10,001 to 20,000 & 56 & 21.5 & 49 or less & 42 & 16.1 \\
\hline 20,001 to 30,000 & 28 & 10.7 & 50 to 249 & 104 & 39.8 \\
\hline 30,001 or more & 13 & 5.0 & 250 or more & 115 & 44.1 \\
\hline Job Tenure & & & $\underline{\text { Sector }}$ & & \\
\hline$\overline{\text { Less than } 1}$ year & 55 & 21.3 & $\overline{\text { Textile }}$ & 90 & 34.3 \\
\hline $1-5$ years & 114 & 44.2 & Furniture & 171 & 65.5 \\
\hline $6-10$ years & 52 & 24.0 & & & \\
\hline $11-20$ years & 25 & 9.7 & Department & & \\
\hline \multirow[t]{7}{*}{21 years or more } & 2 & .8 & Production & 163 & 62.9 \\
\hline & & & Marketing & 27 & 10.4 \\
\hline & & & Accounting & 41 & 15.8 \\
\hline & & & Finance & 3 & 1.2 \\
\hline & & & $\mathrm{HR}$ & 8 & 3.1 \\
\hline & & & $R \& D$ & 2 & .8 \\
\hline & & & Other & 15 & 5.8 \\
\hline
\end{tabular}

Table 1: Demographic Characteristics of the Sample

Leading by example $(\alpha=.89)$ An item was "Leads by example."

Participative decision making ( $\alpha=.94)$ One item was "Encourages work group members to express their ideas/suggestions".

Coaching $(\alpha=.93)$ An item was "Suggests ways to improve my work group's performance."

Informing $(\alpha=31)$ One item was "Explains h9ow my work group fits into the company."

Showing concern/Interacting with the team $(\alpha=91)$ An item was "Shows concern for work group members well-being." As these five dimensions were positively and highly correlated, a composite measure of total leader empowering behaviors was created.

Psychological empowerment

Psychological or personal feelings empowerment was measured by a twelve item scale developed and validated by Spreitzer $(1996,1995)$. This measure tapped four dimensions, each addressed by three items.

Respondents indicated their agreement with each item on a seven-point Likert scale ( $1=$ Very strongly disagree; $4=$ Neutral, $7=$ Very strongly agree).

Meaning $(\alpha=.92)$ "The work I do is meaningful to me."

Competence $(\alpha=.85)$ "I am confident about my ability to do my job."

Self-determination $(\alpha=.85)$ "I have significant autonomy in determining how I do my job." Impact $(\alpha=91$.$) "My impact on what happens in my department is large".$ 
And as these four dimensions were positively and significantly correlated, a composite measure of psychological empowerment was created.

Work and well-being outcomes

Eight work and well-being outcomes were included.

Job satisfaction was assessed by a seven item scale $(\alpha=83)$ developed and validated by Taylor and Bowers (1972). Respondents indicated their agreement with each item on a five-point Likert scale (1-Very dissatisfied, $3=$ Neither satisfied nor dissatisfied; $5=$ Very satisfied. One item was "all in all, how satisfied are you with the persons in your work group?"

Affective commitment was measured by a six item scale $(\alpha=.93)$ developed and validated by Meyer and Allen (1997). Respondents indicated their agreement with each item on a five-point Likert Scale (1=Strongly disagree, $3=$ Neither agree nor disagree; $5=$ Strongly agree). One item was "I am proud to tell others I work at my hotel".

Work engagement

Three aspects of work engagement were assessed using measures created by Schaufeli, et. al, (2002).

Respondents indicated their agreement with each item on a five point Likert scale (1=strongly disagree,

$3=$ neither agree nor disagree, $5=$ strongly agree)

Dedication was measured by five items $(\alpha=.87)$. One item was "I am proud of the work I do."

Vigor was assessed by six items $(\alpha=.87)$ An item was "At my work I feel bursting with energy."

Absorption was measured by six items $(\alpha=.77)$. One item was "I am immersed in my work."

Employee Voice

Employee voice behaviors were measured by a six item scale $(\alpha=.93)$ developed by Van Dyne and LePine (1998). Respondents reported how often they engaged in voice behaviors in their workplaces by indicating the frequency of each item on a five point Likert scale ( $1=$ Never, $3=$ sometime, and $5=$ Very frequently). One item was "I speak up in my workplace with ideas for new projects or changes in the way we do things."

Intent to quit was measured by two items $(\alpha=.91)$ used by Burke (1991). Respondents indicated "yes or no" for both items. One item was "Are you currently looking for a different job in a different organization?"

Employee health complaints was assessed by a 19 item scale $(\alpha=90)$ developed and validated by Quinn and Shepard (1974.) Respondents indicated how often they experienced each complaint on a four-point Likert scale (1=Never, 4=often).

Learning- related outcomes

Workplace learning potential

Workplace learning potential was assess by a twelve item scale developed and validated by Nikolova, Van Ruysseveldt, de Witte and Syroit (2014). It included four potential sources, each measured by three items. Respondents indicated how applicable each item was to their current work situation on a five point Likert scale $(1=$ Not applicable at all; $5=$ completely applicable). Learning potential sources included: Learning through reflection $(\alpha-.88)$ 'In my work I am given the opportunity to contemplate about different work methods; Learning through experimentation $(\alpha=.79)$ "In my job I can try different work methods even if that does not deliver any useful result,"; Learning from colleagues $(\alpha=.85)$ " My colleagues tell me if I make mistakes in my work"; and Learning from supervisors $(\alpha=.88)$ "My supervisor helps me see my mistakes as a learning experience."

Self-perceived employability

Self-perceived f employability was measured by nine items $(\alpha=.83)$ developed and validated by Wittekind, et. al, (2010). Respondents indicated their agreement with each item as they saw themselves at work in a five-point Likert scale (1-strongly agree, 3+Neither agree nor disagree; 5=Strongly agree). One item was "If my organization offered me a possibility to obtain more work experiences, I would take it."

\section{Results}

Personal and work situation characteristics

Table 2 shows the comparisons of males and females on personal and demographic characteristics. The following comments are offered in summary. Significant gender differences were present on eight of the twelve measures. Females were younger, less likely to be married, were more highly educated, had less organizational and job tenures, were at lower organizational levels, and were less likely to have supervisory duties. In addition, females tended to be in part-time positons, and a smaller percentage of females worked in production with more tending to be employed in accounting, marketing and human resources. 


Personal demographics
Age
Marital status
Parental status
Level of education
Work status

Work situation characteristics

Job tenure

Organizational tenure

Organizational level

Organization size

Hours worked

Income

Supervisory duties

\begin{tabular}{|c|c|c|c|c|c|c|}
\hline \multicolumn{3}{|c|}{ Males } & \multicolumn{4}{|c|}{ Females } \\
\hline$\underline{X}$ & $\underline{\mathrm{SD}}$ & $\underline{\mathrm{N}}$ & $\underline{X}$ & $\underline{\mathrm{SD}}$ & $\underline{N}$ & $\underline{\mathrm{P}}$ \\
\hline 2.9 & .80 & 212 & 2.6 & 1.05 & 45 & .05 \\
\hline 1.8 & .42 & 214 & 1.4 & 49 & 45 & .00 \\
\hline 1.1 & .32 & 213 & 1.2 & .38 & 24 & NS \\
\hline 2.2 & .86 & 215 & 2.5 & .84 & 46 & .05 \\
\hline 1.0 & .16 & 215 & 1.1 & .28 & 46 & .10 \\
\hline
\end{tabular}

$\begin{array}{lllllll}2.3 & .94 & 212 & 2.0 & .78 & 46 & .05 \\ 2.1 & .94 & 212 & 1.5 & .78 & 46 & .001 \\ 2.1 & .90 & 215 & 1.8 & .95 & 46 & .05 \\ 2.3 & .72 & 215 & 2.0 & .73 & 46 & .05 \\ 2.2 & .42 & 213 & 2.0 & .26 & 44 & .10 \\ 2.5 & .98 & 215 & 2.4 & 1.15 & 46 & \text { NS } \\ 1.3 & .44 & 215 & 1.5 & .50 & 46 & .01\end{array}$

Table 2: Gender differences on Personal Demographic and Work situation Characteristics

Work experiences, work and learning- related outcomes

Table 3 shows the comparisons of males and females on their work experiences, work outcomes, and learningrelated outcomes. The following comments are offered in summary. First, males and females reported similar perceptions of their supervisor's level of empowering behaviors. Second males reported higher levels on one of the four dimensions of psychological empowerment, Impact. Which was then reflected in males having a higher total psychological empowerment score. Third, males and females reported similar levels of job satisfaction, the work engagement factor of Absorption, organizational commitment, quit intentions and psychological wellbeing. Females indicated significantly lower levels of vigor and dedication, two work engagement dimensions, and engaging in voice behaviors than did their male counterparts. Fourth, males and females reported similar levels of learning opportunities and self-assessed levels of employability.

Additional observations

It is possible that females lower levels of work engagement on vigor and dedication, and their engaging in less voice behaviors, reflected the facts that they had less organizational and job tenures and were in jobs at lower organizational levels. Not surprisingly, individuals at higher organizational levels reported both more supervisory/leader empowerment behaviors and higher levels of their own psychological empowerment. It is possible to instill characteristics of the experiences of these higher level respondents (more influence, more discretion) into lower level jobs as well- one approach to increasing levels of empowerment. 
Leader empowering behaviors

Example

Participation decisions

Informing

Coaching

Showing concern

Total empowering behaviors

$\underline{\text { Psychological Empowerment }}$

Meaning

Competence

Self-determination

Impact

Total Empowerment

Work Outcomes

Job satisfaction

Vigor

Dedication

Absorption

Organizational commitment

Voice behaviors

Intent to quit

Health complaints

Learning-related outcomes

Reflection
Experimentation
Co-workers
Supervisors
Self-related Employability

\begin{tabular}{|c|c|c|c|}
\hline Males & & & Females \\
\hline$\underline{X}$ & $\underline{\mathrm{SD}}$ & $\underline{\mathrm{N}}$ & $\underline{X}$ \\
\hline$\overline{19} .2$ & $\overline{4.58}$ & $\overline{215}$ & $\overline{19} .2$ \\
\hline 18.8 & 5.43 & 215 & 19.5 \\
\hline 18.8 & 5.09 & 215 & 19.2 \\
\hline 18.5 & 5.27 & 215 & 19.3 \\
\hline 18.4 & 5.37 & 215 & 19.5 \\
\hline 93.6 & 23.62 & 215 & 96.6 \\
\hline
\end{tabular}

$\begin{array}{lll}\frac{\mathrm{SD}}{3.28} & \frac{\mathrm{N}}{46} & \underline{\mathrm{P}} \\ 4.43 & 46 & \mathrm{NS} \\ 4.37 & 46 & \mathrm{NS} \\ 4.70 & 46 & \mathrm{NS} \\ 4.77 & 46 & \mathrm{NS} \\ 19.43 & 46 & \mathrm{NS}\end{array}$

$\begin{array}{lllllll}13.4 & 2.35 & 215 & 12.9 & 2.92 & 46 & \text { NS } \\ 13.0 & 2.31 & 215 & 12.5 & 2.52 & 46 & \text { NS } \\ 11.7 & 2.70 & 215 & 11.3 & 2.57 & 46 & \text { NS } \\ 11.8 & 3.13 & 215 & 10.2 & 3.17 & 46 & .01 \\ 49.9 & 8.59 & 215 & 46.9 & 7.89 & 46 & .05\end{array}$

$\begin{array}{lllllll}25.4 & 5.08 & 215 & 26.4 & 5.25 & 46 & \text { NS } \\ 23.1 & 5.21 & 215 & 21.1 & 5.34 & 46 & .05 \\ 20.1 & 4.34 & 215 & 18.2 & 5.13 & 46 & .01 \\ 21.1 & 4.79 & 215 & 20.1 & 4.98 & 46 & \text { NS } \\ 24.3 & 6.01 & 215 & 24.1 & 5.45 & 46 & \text { NS } \\ 23.5 & 5.78 & 215 & 21.2 & 5.58 & 46 & .05 \\ 3.5 & .86 & 215 & 3.6 & .75 & 46 & \text { NS } \\ 34.7 & 10.87 & 215 & 35.0 & 10.36 & 46 & \text { NS }\end{array}$

$\begin{array}{lllllll}10.71 & 3.40 & 215 & 10.4 & 3.73 & 46 & \text { NS } \\ 0.9 & 3.32 & 215 & 9.9 & 3.27 & 46 & .10 \\ 11.6 & 3.30 & 215 & 11.3 & 3.87 & 46 & \text { NS } \\ 11.1 & 3.58 & 215 & 10.9 & 3.95 & 46 & \text { NS } \\ 27.8 & 5.64 & 215 & 27.7 & 4.68 & 46 & \text { NS }\end{array}$

Table 3: Gender differences on work and learning - related outcomes

\section{Discussion}

We found considerable support for our three hypotheses (see Tables 2 and 3), consistent with some previous gender research conclusions in studies of other occupations in Turkey. There were considerable gender differences on personal demographic and work situation characteristics but relatively few differences on perceptions of leadership behaviors, a range of work outcomes, and indicators of workplace learning opportunities associated with the concept of employability. Thus it may be possible for women to transcend obvious societal and cultural biases and obstacles in achieving work experiences and work outcomes similar to their male colleagues.

The few significant gender differences likely reflected the fact that men were at higher organizational levels and had longer organizational tenures. And although the differences were not statistically significant, a slightly higher percentage of men were working in production and a slightly lower percentage of men were working in marketing, accounting and human resources.

\subsection{Practical implications}

The absence of gender differences on important perceptions of work experiences, work outcomes, and learning-related opportunities and benefits, while not suggesting that women and men have identical work experiences, clearly supports the conclusion that women in the present study, and in others, have satisfying work experiences and responses. The responsibility then in workplaces is to continue to support the future career possibilities of their qualified male and female employees similarly (Hewlett \& Rashid, 201'1). This would involve equal access to both formal and informal learning and training opportunities, as well as considering women for advancement on the same basis as their male colleagues (Burke, Koyuncu \& Fiksenbaum, 2007a, 2006).

\subsection{Limitations of the research}

The present research has limitations which should be noted to better assess the results. First, all data were collected using self-report questionnaires with the possibility of response set tendencies and common method biases. Second, although the sample was relatively large, all respondents came from firms in the same industrial 
region of Turkey thus the extent to which our findings would apply to firms in other regions is indeterminate. Third, the females sample however was relatively small. Finally, the majority of our respondents had some level of supervisory responsibility and were generally satisfied with their work situations making it unclear the extent to which our findings would be replicated in a sample of non-supervisory employees.

\subsection{Future research directions}

It would be important to undertake a similar study focusing on women and men without supervisory responsibilities to assess the generalizability of the present findings. In addition, including measures that more directly address bias and discrimination would supplement what this and other earlier studies have shown. Finally, continuing this line of work hut examining gender in other occupations would be informative.

An important question that remains unexplored is the apparent gap or disconnect between the experiences of women working in the occupations under study and the wider societal context which embodies elements of bias and obstacles for women in the workplace.

\section{References}

- Arnold, Arad, Rhoades, and Drasgow, 2000. "The empowering leadership questionnaire: The construction and validation of a new scale for measuring leader behavior", Journal of Organizational Behavior, 21, p. 249-269.

- Aycan, 2004."Key success factors for women in management in Turkey", Applied Psychology: An International Review, 53, p.453-477.

- Besler, Oruc, 2010. "Women managers in the print media in Turkey", Anadolu University Journal of Social Sciences, 10, p. 17-38.

- Bowen and Lawler, 1995. "Empowering service workers”, Sloan Management Review, 36, p. 73-84.

- Bowen and Lawler, 1992. "The empowerment of service workers: What, why, how and when", Sloan Management Review, 33, p. 31-40.

- Boydak and Akpinar, 2002. "The success of women administrators in school administration", Firat University Journal of Social Science, 12, p. 219-234.

- Burke, 1991. "Early work experiences of female and male managers and professionals: Reasons for optimism?", Canadian Journal of Administrative Sciences, 8, p. 224-230.

- Burke and Koyuncu, 2013. "Women in management in Turkey: Opportunities and challenges" In M. Paludi (ed.) Women and management: global issues and promising solutions pp. 239-263, Praeger, Santa Barbara. CA.

- $\quad$ Burke, Koyuncu and Fiksenbaum, 2009. "Gender differences in work experiences, satisfactions and wellbeing among physicians in Turkey”, Gender in Management: An International Journal, 24, p. 70-91.

- $\quad$ Burke, Koyuncu and Fiksenbaum, 2007a. "Career priority patterns among managerial and professional women in Turkey: Benefits of putting career first?”, Women in Management Review, 22, p.405-417.

- $\quad$ Burke, Koyuncu and Fiksenbaum, 2006. “Organizational practices supporting women's career advancement and their satisfaction and well-being in Turkey", Women in Management Review, 21, p.610-624.

- $\quad$ Burke, Koyuncu, Singh, Alayoglu and Koyuncu, 2011. "Gender differences in work experiences and work outcomes among Turkish managers and professionals: Continuing signs of progress?", Gender in Management: An International Journal, 27(1), p. 23-35.

- Crouse, Doyle, and Young, 2011. "Workplace learning strategies, barriers, facilitators and outcomes: A qualitative study among human resource management professionals", Human Resource Development International, 14, p. 39-55.

- DeCuyper and DeWitte, 2011. "The management paradox: Self-rated employability and organizational commitment and performance", Personnel Review, 40, p. 152-172.

- Dewettnick and van Ameijde, 2011. "Linking leadership empowerment behavior to employee attitudes and behavioral intentions", Personnel Review, 40, p. 284-305.

- Guney, Gohar, Lailic and Akinci, 2006. "Attitudes toward women managers in Turkey and Pakistan", Journal of International Women's Studies, 8, p. 194-211.

- Hewlett and Rashid, 2011. Wining the war for talent in emerging markets: Why women are the solution. Harvard Business School Press, Boston, MA.

- Kabasakal, Aycan and Karakas, 2004. "Women in management in Turkey” In Davidson and Burke (eds) Women in management worldwide: Facts, figures and analysis. p. 223-253, Gower, Aldershot.

- Kabasakal, Aycan, Karakas and Maden, 2011. "Women in management in Turkey" In Davidson and Burke (eds.) Women in management worldwide: Progress and prospects p. 317-330, Gower, Aldershot. 
- Koyuncu, Burke and Fiksenbaum, 2006. "Work experiences and satisfaction of male and female professors in Turkey: signs of progress?", Equal Opportunities International, 25, p. 38-47.

- Lawler, 1992. The ultimate advantage: Creating the high involvement organization. Jossey-Bass, San Francisco.

- Lawler, Mohrman, and Ledford, 1995. Creating high performance organizations: Practices and results of employee involvement and total quality management in Fortune 1000 companies. Jossey-Bass, San Francisco.

- Lohman, 2009. "A survey of factors influencing the engagement of information technology professionals in informal learning activities”, Information Technology, Learning and Performance Journal, 25, p. 43-53.

- Lohman, 2006. "Factors influencing teachers' engagement in informal learning activities", Journal of Workplace Learning, 18, p. 1141-1156.

- Lohman, 2005. "A survey of factors influencing the engagement of two professional groups in informal workplace learning activities", Human Resources Development Quarterly, 16, p. 501-527.

- Lohman, 2000. "Environmental inhibitors to informal learning in the workplace: A case study of public school teachers", Adult Education Quarterly, 50, p. 83-1201.

- Marsick and Watkins, 2003. "Demonstrating the value of an organization's learning culture: The dimensions of the Learning Organization Questionnaire", Advances in Developing Human Resources, 5, p. 132-151.

- Menon, 2001. "Employee empowerment: An integrative psychological approach", Applied Psychology: An International Review, 50, p. 153-180.

- Meyer and Allen, 1997. Commitment in the workplace: Theory, research, and applications. Sage Publications, Thousand Oaks, CA:

- $\quad$ Nikolova, I., Van Ruysseveldt, J., De Witte, H., \& Syrioit, J. (2014) “Work-based learning: Development and validation of a scale measuring the learning potential of the workplace (LPW)" Journal of Vocational Behavior 84, p. 1-10.

- Ozbilgin, 2000. "The way forward for equal opportunities by sex in employment in Turkey and Britain", Management International Review, 7, p. 55-65.

- Ozbilgin and Healy, 2004. "The gendered nature of career development of university professors: The case of Turkey", Journal of Vocational Behavior, 64, p. 358-371.

- Ozbilgin and Woodward, 2004a. Banking and gender: Sex equality in the financial services in Britain and Turkey. L. B. Tauris, London.

- Ozbilgin and Woodward, 2004b. "Belonging" and "otherness": Sex equality in banking in Turkey and Britain”, Gender, Work and Organization, 11, p. 668-688.

- Quinn and Shepard, 1974. The 1972-73 Quality of Employment Survey. MI Institute for Social Research, University of Michigan, Ann Arbor.

- Quinn and Spreitzer, 1997. "The road to empowerment: seven questions every leader should consider", Organizational Dynamics, 26, p. 37-49.

- Rothwell and Arnold, 2007. "Self-perceived employability: Development and validation of a scale", Personnel Review, 37, p. 23-41.

- $\quad$ Salas and Von Glinow, 2008. "Fostering organizational learning: Creating and maintaining a learning culture" In Burke and Cooper (eds) Building more effective organizations. p. 207-227. Cambridge University Press. Cambridge.

- Sanal, 2008. "Factors preventing women's advancement in management in Turkey", Education, 128, p. 380391.

- Schaufeli, Salanova, Gonzalez-Roma and Bakker, 2002. "The measurement of engagement and burnout: A two sample confirmatory factor analysis approach", Journal of Happiness Studies, 3, p. 71-92.

- Seibert, Wang and Courtright, 2011. "Antecedents and consequences of psychological and team empowerment in organizations. A meta-analytic review”, Journal of Applied Psychology, 96, p. 981-1003.

- Spreitzer, 1997. "Toward a common ground in defining empowerment", Research in Organizational Change and Development, 10, p. 31-62.

- Spreitzer, 1996. "Social structural characteristics of psychological empowerment", Academy of Management Journal, 39, p. 483-504.

- Spreitzer, 1995. "Psychological empowerment in the workplace: Dimensions, measurement, and validation", Academy of Management Journal, 38, p. 1442-1465. 
- Taylor and Bowers, 1972. Survey of organizations: A machine-scored standardized questionnaire instrument, MI.: Institute for social Research, Ann Arbor.

- United Nations Development Programme, 2008. Human development report 2007-2008, Oxford University Press, New York.

- Van Dyne and LePine, 1998. "Helping and voice extra-role behaviors: Evidence of construct and predictive validity", Academy of Management Journal, 41, p. 108-119.

- Van der Heijden, de Lange, Demerouti and van der Heijde, 2009. "Age effects on the employability-career success relationship”, Journal of Vocational Behavior, 74(2), p. 156-164.

- Wittekind, Raeder and Grote, 2010. "A longitudinal study of determinants of perceived employability”, Journal of Organizational Behavior, 31, p. 566-586.

- Woodward and Ozbilgin, 1999. "Sex equality in the financial services sector in Turkey and the UK", Women in Management Review, 14, p. 325-332.

- Zemke and Schaaf, 1989. The service edge: 101 companies that profit from customer care. New American Library, New York. 